\title{
Modeling climate change impacts on overwintering of Spodoptera exigua Hübner in regions of China
}

\author{
Xia-Lin Zheng1, Qing-Cheng Huang ${ }^{1}$, Wan-Zheng Cao ${ }^{1}$, Wen Lu ${ }^{1 *}$, Guo-Quan Wang ${ }^{1}$, Shu-Zhong Yu², \\ Zhen-De Yang ${ }^{2}$, and Xiao-Ping Wang ${ }^{3}$
}

Inferential models are usually used to evaluate the effect of winter warming on range expansion of insects. Generally, correlative approaches used to predict changes in the distributions of organisms are based on the assumption that climatic boundaries are fixed. Spodoptera exigua Hübner (Lepidoptera: Noctuidae) overwinters as larvae or pupae in China regions . To understand the climate change impacts on overwintering of this species in regions of China, CLIMEX and Arc-GIS models were used to predict possible changes of distribution based on temperature. The climate change projection clearly indicated that the northern boundary of overwintering for S. exigua will shift northward from current distribution. Thus, the ongoing winter warming is likely to increase the frequency of S. exigua outbreaks.

Key words: Global warming, integrated pest management, overwintering regions, population density, range distribution.

\section{INTRODUCTION}

Overwhelming evidence indicates that global warming is an indisputable fact. It involves simultaneous and complex changes of many environmental variables, but primarily reflects air temperature. Numerous studies have shown that the annual average temperature of the earth will increase $1{ }^{\circ} \mathrm{C}$ by 2025 and the probable rise in temperature by the end of the century is expected to reach $3{ }^{\circ} \mathrm{C}$ (Solomon et al., 2007). Global warming develops faster in winter than in summer, and is greatest at high latitudes (Roy and Sparks, 2000). For example, in the Northern Hemisphere, from 1951 to 1990 average winter minimum temperature rose $2.9^{\circ} \mathrm{C}$ while summer maximum temperature increased $1.3{ }^{\circ} \mathrm{C}$ (Karl et al. 1993). Insects are poikilothermic organisms, whose body temperature depends directly on ambient temperature, and so are particularly sensitive to temperature changes. Concern over the implications of climate change for insects has led to the use of bioclimatic models to predict their distribution under future climate conditions (Acevedo et al., 2011; Aragón and Lobo, 2012) and have discussed the effects of global warming on insects (Hill et al., 2011), in their extension of geographical range and development season; increasing overwintering

${ }^{1}$ Guangxi University, College of Agriculture, Nanning 530004, China. "Corresponding author (luwenlwen@163.com).

${ }^{2}$ Guangxi University, College of Forestry, Nanning 530004, China.

${ }^{3}$ Huazhong Agricultural University, College of Plant Science and Technology, Wuhan 430070, China.

Received: 1 November 2014.

Accepted: 19 March 2015.

doi:10.4067/S0718-58392015000400009 survival, number of generations, risks of invasions by migrant pests, changing in population growth rate, crop pest synchrony, interspecific interactions, introduction of alternative hosts, and over wintering hosts (Porter et al., 1991). However, the obvious effects of climate warming (especially in winter warming) on insects is that it allows range expansion, with northward advances into "colder areas" (Hill et al., 2011), like in the field skipper, Atalopedes campestris (Boisduval) (Lepidoptera: Hesperidae) (Crozier, 2003).

The beet armyworm, Spodoptera exigua Hübner (Lepidoptera: Noctuidae), is a persistent agricultural pest in many areas of the world. This species escapes freezing (Zheng et al., 2011), that overwinters without diapause (He et al., 2011). Our previous study showed that the southern and northern overwintering boundaries of $S$. exigua in China are near the Tropic of Cancer (about $23.5^{\circ} \mathrm{N}$ lat) and the Yangtze River valley (about $30^{\circ} \mathrm{N}$ lat), and suggested that the current range of $S$. exigua may be limited by low temperature during winter (Zheng et al., 2012). However, little is known whether S. exigua is responding to global warming by shifting its overwintering distribution to higher latitudes, especially during winter. Such knowledge is crucial for reliable forecasting of potential future distribution of biodiversity under current climate warming.

CLIMEX (Hearne Scientific Software, South Yarra, Victoria, Australia) has been proven to be a reliable prediction model (Kriticos and Randall, 2001). The model is based on the climate requirements of the species in the areas where they live to estimate their potential geographical distribution and seasonal abundance. So far, it has been widely used to determine the potential geographical distribution of poikilothermal organisms, 
such as the gypsy moth, Lymantria dispar (Peterson et al., 2007) and multicolored Asian lady beetle, Harmonia axyridis (Pallas) (Poutsma et al., 2008). In addition, this model assumes that species at a given location experience one season that is favorable for population growth, and one that is unfavorable (Sutherst et al., 2004). These are referred to as growth or survival and stress seasons, respectively. While the occurrence during winter may be limited by either temperature or other factors, the Ecoclimatic Index (EI) is usually related to the insect growth responding to climate, and can be used to describe the population dynamic.

Therefore, the objective of this study was to model with CLIMEX the impacts of warming on overwintering of $S$. exigua in regions of China. These results could provide helpful information to understand the relationship between overwintering biology of this insect and climate warming.

\section{MATERIAL AND METHODS}

CLIMEX model (version 2.0) was used to predict the potential geographical distribution of an organism combined with meteorological data through a series of annual indices (Sutherst et al., 2004). It operates in two modes: Compare Locations and Compare Years. In the former, it enables the user to predict the potential geographical distribution of a species or a pair of species in relation to climate based on its climatic preferences, while in the latter the response to climates in different years at the same place is compared. In CLIMEX 2597 locations (meteorological stations) worldwide are included, of which 86 locations are recorded in China. Climatic data associated with these locations span the period 1960-1990.

Species parameters inferred from literature and experimental values are part of the input in the CLIMEX model, and describe the modeled organism response to climatic data. In CLIMEX, an annual Growth Index describes the potential of growth for a population during the favorable season. There are four stress indices (cold, hot, wet, and dry), and in some cases the interactions between them (cold-wet, cold-dry, heat-wet, and heatdry) describe the extent to which the population is reduced during the unfavorable season. Growth and stress indices are combined into an EI, which is scaled from 0 to 100 to give an overall measure of climatic suitability for the species concerned. Generally, an EI $>0$ indicates that the location is possible for species growth, and an EI of more than 30 represents a very favorable climate for a species (Sutherst et al., 2004). In the current study, values EI > 30 are considered more suitable for S. exigua.

In this study, the method and step for modeling the climate change impacts on overwintering of S. exigua in regions of China during winter by CLIMEX and Arc-GIS (Esri, Redlands, California, USA) were provided by (i) Creating a new meteorological database and location file of China with the .loc/.met format, total of 758 stations (Figure 1). The detailed process of importing the new MetManager database file into CLIMEX is described in the User's Guide (Sutherst et al., 2004). (ii) Inputting biological parameters for projecting overwintering regions of S. exigua in China (Table 1). Sources of the biological information used in this study were detailedly described in our previous study (Zheng et al., 2012). (iii) Creation of incremental scenarios for temperature $(+1,+2$ and + $3{ }^{\circ} \mathrm{C}$ ), and were only applied in winter monthly values (minimum and max temperature changes) in CLIMEX. (iv) The final EI for S. exigua generated for China, and the output files were integrated into the Arc-GIS 9.3. Then, the interpolation method of Kriging within Arc-GIS 9.3 was used to obtain the EI surfaces (Tonnang et al., 2010). The method provided a visual description of species ranges rather than simple points, particularly for poorly sampled regions (Anderson et al., 2002; Tonnang et al., 2010).

Table 1. CLIMEX parameter values used for Spodoptera exigua ${ }^{1}$.

\begin{tabular}{ll}
\hline Index & \multicolumn{1}{c}{ Parameter } \\
\hline Temperature & DV0, lower threshold $\left({ }^{\circ} \mathrm{C}\right)$ \\
& DV1, lower optimum temperature $\left({ }^{\circ} \mathrm{C}\right)$ \\
& DV2, upper optimum temperature $\left({ }^{\circ} \mathrm{C}\right)$ \\
Moisture & DV3, upper threshold $\left({ }^{\circ} \mathrm{C}\right)$ \\
& SM0, lower soil moisture threshold \\
& SM1, lower optimum soil moisture \\
& SM2, upper optimum soil moisture \\
Cold stress & SM3, upper soil moisture threshold \\
& TTCS, temperature threshold $\left({ }^{\circ} \mathrm{C}\right)$ \\
Heat stress & THCS, stress accumulation rate (per week) \\
& TTHS, temperature threshold $\left({ }^{\circ} \mathrm{C}\right)$ \\
Dry stress & THHS, stress accumulation rate (per week) \\
& SMDS, threshold soil moisture \\
Wet stress & HDS, stress accumulation rate (per week) \\
Annual heat sum & SMWS, threshold soil moisture \\
\hline
\end{tabular}

${ }^{1}$ Data cited from Zheng et al. (2012).

DV: Development temperature, SM: soil moisture, TTCS: cold stress temperature threshold, THCS: cold stress accumulation rate, TTHS: temperature threshold, THHS: heat stress accumulation rate, SMDS: dry stress threshold, HDS: dry stress rate, SMWS: wet stress threshold, HWS: wet stress rate, PDD: day degree threshold. 


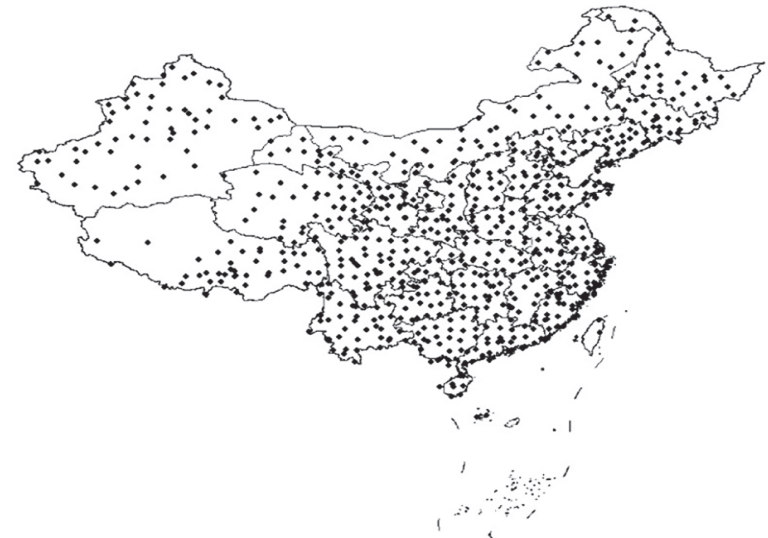

Figure 1. Geographical distribution of the 758 meteorological stations used in this study.

Regression analysis of the annual and winter temperature rise pattern from 1951 through 2012 at the northern boundary of $S$. exigua overwintering (Wuhan City, Hubei Province, China) was done using SPSS 16.0 (IBM Corporation, Armonk, New York, USA).

\section{RESULTS}

Compared to current climate conditions, results indicated that S.exigua will increase ranges and relative abundances for winter temperature increasing from 1 to $3{ }^{\circ} \mathrm{C}$ (Figure 2 ). Range expansion will occur in westerly and northerly directions. And then, 14.9\%, $17.7 \%$, and $20.3 \%$ of modeled areas were predicted to have EI values $>30$ at + $1,+2$ and $+3{ }^{\circ} \mathrm{C}$ scenarios, respectively.

Under $+1{ }^{\circ} \mathrm{C}$ scenario, overwintering regions in northern of Fujian, Guangdong, Guangxi, and Hunan provinces; southland of Yunnan, Guizhou, Hunan, Jiangxi, Zhejiang, and Chongqing provinces/cities; southeastern regions of Zhejiang, Guizhou, Chongqing, and Sichuan provinces are becoming perennial damage regions from overwintering regions. Meanwhile, most parts of southern suitable overwintering regions (washy areas) are becoming favourable areas (darker areas). For instance, the EI values increase from 6 to 24 in Wuhan City (Hubei Province). Importantly, the overwintering regions expand occurred northerly direction (Figure $2 b$ ). For example, the northern boundary of overwintering in S. exigua located at Suzhou City $\left(31.19^{\circ} \mathrm{N}, 120.37^{\circ} \mathrm{E}\right)$ in Jiangsu Province under current climate, but the boundary could expand to near Yangzhou City $\left(32.23^{\circ} \mathrm{N}, 119.26^{\circ} \mathrm{E}\right)$ when winter temperature increases $1{ }^{\circ} \mathrm{C}$.

There is a similar trend that perennial damage and overwintering regions shift expansion northward under $+2{ }^{\circ} \mathrm{C}$ scenario (Figure 2d). Under this conditions, overwintering regions in northland of Fujian, Guangdong, Guangxi, and Hunan provinces; southland of Yunnan, Guizhou, Hunan, Jiangxi, Zhejiang, Jiangsu, Hubei, and Chongqing provinces/cities; southeastern regions of Zhejiang, Hubei, Guizhou, Chongqing, and Sichuan provinces are becoming perennial damage regions from overwintering regions. The obvious change of overwintering regions was that they expanded northerly in Henan Province, and the edge shift distance was about $150 \mathrm{~km}$ (From Xixian to Huaiyang counties).

Finally, under the $+3{ }^{\circ} \mathrm{C}$ scenario, most parts of the southern regions of the Yangtze River valley are almost becoming perennial damage regions (Figure 2f). It is a remarkable fact that the northern overwintering boundaries of $S$. exigua shifted northerly in Shanxi, Anhui, and Jiangsu Provinces, and the northernmost sites were Jinghe and Yongzhen towns, and Sheyang city in these provinces, respectively.

\section{DISCUSSION}

Liu et al. (2004) considered that changes in temperature in China increased in all seasons according to 305 meteorological stations from 1955 to 2000 , especially in the last decade of the twentieth century. Meanwhile, warming was most pronounced during winter in the north. In this study, regression was highly significant when mean annual and winter temperature (December to February) were used, showing a total increase of approximately $2{ }^{\circ} \mathrm{C}$ (annual) and $3{ }^{\circ} \mathrm{C}$ (winter) in the Wuhan City, Hubei province (northern boundary of overwintering) during 1951-2012 periods (Figure 3).

Many studies have illustrated that climate change has and will continue to influence species distributions (Tran et al., 2007). Our study, using CLIMEX and Arc-GIS models clearly indicated that population abundance changed and the northern boundary of overwintering in S. exigua shifted northward compared with current climatic condition.

\section{Population abundance}

To the best of our knowledge, global warming is the dominant factor affecting the abundance of many insects. Warming conditions may influence insect populations by extending the growing season, altering the timing of emergence, increasing growth and development rates, shorting generation times, and reducing overwintering mortality (Porter et al., 1991; Kurz et al., 2008). Undoubtedly, climate warming (especially in winter warming) could result in no obvious hibernation and/or reducing the incidence of diapause in some insect species (Bale and Hayward, 2010) compared with those under the current climate conditions in same regions, so that some (hibernation species) could develop and reproduce normally during winter, and/or others (diapause species) can survive winter outside of diapause, which avert diapause may provide a selective advantage (Tougou et al., 2009). Most importantly, lower mortality during winter of insects due to warmer winter temperatures could play an important role in increasing insect populations (Harrington et al., 2001). 

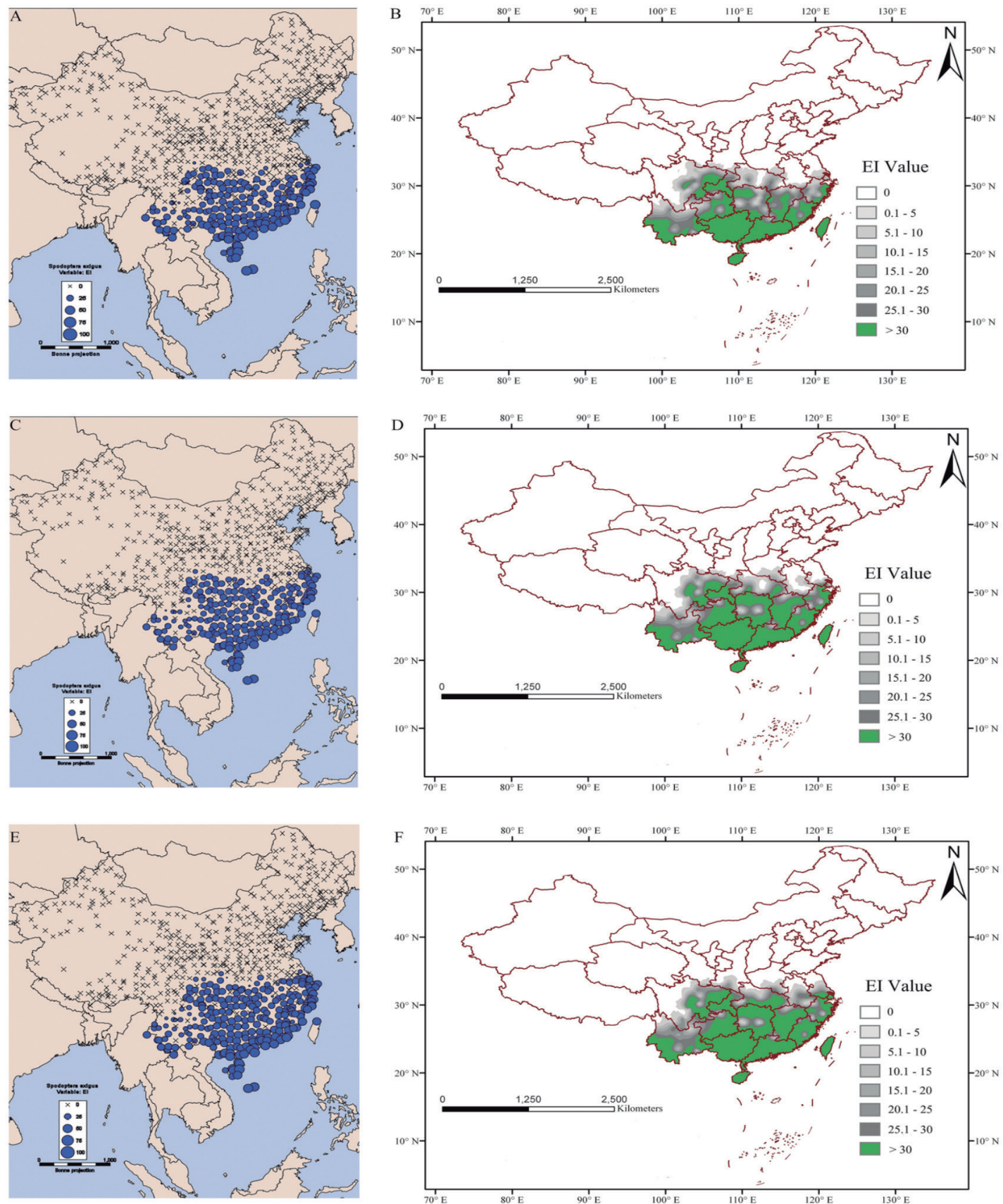

Figure 2. Predicted distribution and abundance of Spodoptera exigua for potential climate change in winter. $+1{ }^{\circ} \mathrm{C}(\mathrm{A}$ and $\mathrm{B}),+2{ }^{\circ} \mathrm{C}(\mathrm{C}$ and $\mathrm{D})$, and $+3{ }^{\circ} \mathrm{C}(\mathrm{E}$ and F). The map (B, D, and F) was constructed by Arc-GIS using the ecoclimatic indices (EI) obtained from climate change scenarios in CLIMEX (A, C, and E). In the subdivided figures (A, C, and E) crosses indicate unsuitable over-wintering locations, and spots represent EI > 0. The larger spot indicate that the climate at the station is more suitable for development or over-wintering of this species.

In this study, results also demonstrated that overwintering regions (suitable) under the current climate would become perennial damage regions (favorable) as winter warming. For instance, the EI value of $S$. exigua in Jinggangshan City (Jiangxi Province) increased from 10 (current climate condition) to $31\left(+1{ }^{\circ} \mathrm{C}\right.$ scenario $)$, to $34\left(+2{ }^{\circ} \mathrm{C}\right.$ scenario $)$, and to $35\left(+3{ }^{\circ} \mathrm{C}\right.$ scenario). The same tendency appeared in
Naxi (Sichuan Province), Pengshui (Sichuan Province), and Cixi (Zhejiang Province), etc.

However, climate warming is not always beneficial for population abundance. Our results from this study illustrated that the EI value was negative correlation with winter warming in some regions near Equator, such as Taipei, Sanya, and Xisha, etc. We speculated that the species could not adapt to the high temperature in these 


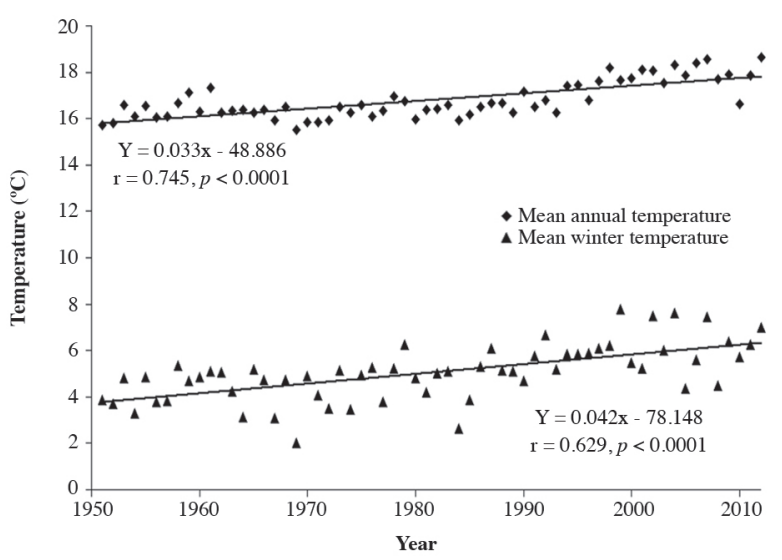

Figure 3. Annual and winter temperature rise pattern during 19512012 periods at Wuhan (Hubei province, China). This analysis was performed using SPSS 16.0. Each point represents an average temperature. The equation, $r$, and $P$ are shown in the figure. When $P<0.05$, it means the regression is significant. Air temperature data provided by Climate Data Centre, China Meteorological Administration.

regions, or warm temperature could induce faster rate of metabolism in the individuals and the nutrient reserves would be exhausted earlier. In fact, previous studies had recorded this fact. For instance, populations of L. dispar could collapse in the USA after winters where the number of warm days was high (Roberts et al., 1993).

\section{Range expansion}

Predicting the responses of various species to climate change is an extremely difficult challenge. It needs a clear understanding of how diverse biotic and abiotic factors interact to determine species' distributions. We admit that range expansion of species can be caused by several abiotic and biotic factors, such as synchrony of insect and their host plant phenology, predators and parasites, human activity, and climate change, etc. (Cammell and Knight, 1992). However, the phenomenon which boundary expand northerly due to climate warming is undisputed fact and has been validated in some species, especially for cold-limited species, such as butterflies (Parmesan et al., 1999), moths (Crozier, 2003), dragonflies and damselflies (Hickling et al., 2005; 2006). Results from our previous studies suggested that the survival of the beet armyworm was currently limited in China due to lack of cold tolerance (Zheng et al., 2011; 2012). In the present study, results apparently showed that winter warming could shift the overwintering boundary of $S$. exigua in a northerly direction. Range expansion of northern boundaries was about $2^{\circ}, 3^{\circ}$, and $5^{\circ}$ northward under $+1{ }^{\circ} \mathrm{C},+2{ }^{\circ} \mathrm{C}$, and $+3{ }^{\circ} \mathrm{C}$ scenarios, respectively.

Furthermore, the southern boundary of overwintering regions in S. exigua has synchronously moved northward as temperature rise, because air temperature in these southern provinces is so suitable for this species to grow, develop and reproduce that they did not need hibernate during winter for escaping the extreme temperature, and reproduce and damage throughout the whole year. Thus, these regions $(E I>30)$ changed from overwintering to perennial damage regions.

\section{Population outbreak}

Recent studies of insects have linked population outbreaks to phenological changes in insect life histories brought about by global climate change (Hódar and Zamora, 2004; Johnson et al., 2010). For example, in a study of outbreak origins and associated climatic data, Ives (1973) was able to determine that climate controls for both the initiation and cessation of the forest tent caterpillar, Malacosoma disstria outbreaks. The catastrophic outbreaks caused by climatic warming maybe link to (a) increase winter survival population densities; (b) reduce the level of parasitism of caterpillars, which in turn may increase the frequency and intensity of herbivore outbreaks (Stireman et al., 2005).

Although S. exigua is an intermittence outbreak species in China (Wen et al., 2011), processes responsible for triggering $S$. exigua outbreaks remain poorly understood. We are worried that winter warming could be more propitious to an outbreak of S. exigua, because evidence that the winter temperature can influence the outbreak of insect pests has been detected in previous studies (Neuvonen et al., 1999; Johnson et al., 2010). Neuvonen et al. (1999) considered that minimum winter temperatures are probably critical in explaining the outbreak areas. In this study, historical climatic data approved that winter warming is the truth (Figure 3), and suggested a long trend toward warmer winter temperatures in the future. As we know, temperature directly affects insect population dynamics through modification of developmental rates and reproduction. Meanwhile, higher winter temperatures have the potential to increase survival of many overwintering species (Bale et al., 2002). Consequently, the ongoing winter warming is thus likely to increase the frequency of outbreaks of S. exigua.

\section{CONCLUSIONS}

Our results showed that the population abundance was changed and the northern boundary of overwintering in Spodoptera exigua shifted northward due to winter warming. However, projecting from models still deserved to improve. On the one hand, we are uncertain whether or not a longer time span will be available for pests to develop each year. While temperatures may be favorable for insect development for a longer time span, the phenology of most insects is coupled with crop phenology and physiology which might remain limiting factors for pest development. On the other hand, rainfall has become less predictable in many regions and irrigation water is less freely available. This does mean that less water is often being applied to crops and in a more targeted manner. The impact of this shift in practice is not clearly known. 


\section{ACKNOWLEDGEMENTS}

We are grateful to Climate Data Centre, China Meteorological Administration, for providing the historical climate data for this study, and also thank anonymous referee and editor for their valuable comments on an earlier version. The research was partially supported by the Training Programs of Innovation and Entrepreneurship for Undergraduates of Guangxi University (2014026).

\section{LITERATURE CITED}

Acevedo, P., F. Ruiz-Fons, R. Estrada, A.L. Márquez, M.A. Miranda, C. Gortázar, et al. 2011. A broad assessment of factors determining Culicoides imicola abundance: modelling the present and forecasting its future in climate change scenarios. PLoS ONE 5:e14236.

Anderson, R.P., M. Gómez-Laverde, and A.T. Peterson. 2002. Geographical distributions of spiny pocket mice in South America: insights from predictive models. Global Ecology and Biogeography 11:131-141.

Aragón, P., and J.M. Lobo. 2012. Predicted effect of climate change on the invasibility and distribution of the Western corn root-worm. Agricultural and Forest Entomology 14:13-18.

Bale, J.S., and S.A.L. Hayward. 2010. Insect overwintering in a changing climate. The Journal of Experimental Biology 213:980-994.

Bale, J.S., G.J. Masters, I.D. Hodkinson, C. Awmack, T.M. Bezemer, V.K. Brown, et al. 2002. Herbivory in global climate change research: direct effects of rising temperature on insect herbivores. Global Change Biology 8:1-16.

Cammell, M.E., and J.D. Knight. 1992. Effects of climate change on the population dynamics of crop pests. Advances of Ecological Research 22:117-162.

Crozier, L. 2003. Winter warming facilitates range expansion: cold tolerance of the butterfly Atalopedes campestris. Oecologia 135:648-656.

Harrington, R., R. Fleming, and I.P. Woiwood. 2001. Climate change impacts on insect management and conservation in temperate regions: can they be predicted? Agricultural and Forest Entomology 3:233-240.

He, H.M., H.Z. Yang, L. Xiao, and F.S. Xue. 2011. Effect of temperature and photoperiod on developmental period and reproduction of Spodoptera exigua. Jiangxi Plant Protection 34:93-96 (In Chinese).

Hickling, R., D.B. Roy, J.K. Hill, R. Fox, and C.D. Thomas. 2006. The distributions of a wide range of taxonomic groups are expanding polewards. Global Change Biology 12:450-455.

Hickling, R., D.B. Roy, J.K. Hill, and C.D. Thomas. 2005. A northward shift of range margins in British Odonata. Global Change Biology 11:502-506.

Hill, J.K., H.M. Griffiths, and C.D. Thomas. 2011. Climate change and evolutionary adaptations at species' range margins. Annual Review of Entomology 56:143-159.

Hódar, J.A., and R. Zamora. 2004. Herbivory and climatic warming: a Mediterranean outbreaking caterpillar attacks a relict, boreal pine species. Biodiversity and Conservation 13:493-500.

Ives, W.G.H. 1973. Heat units and outbreaks of the forest tent caterpillar, Malacosoma disstria (Lepidoptera: Lasiocampidae). Canadian Entomologist 105:529-543.

Johnson, D.M., U. Buntgen, D.C. Frank, K. Kausrud, K.J. Haynes, A.M. Liebhold, et al. 2010. Climatic warming disrupts recurrent Alpine insect outbreaks. Proceedings of the National Academy of Sciences USA 107:20576-20581.

Karl, T.R., P.D. Jones, R.W. Knight, G. Kukla, M. Plummer, V. Razuvayev, et al. 1993. A new perspective on recent global warming: asymmetric trends of daily maximum and minimum temperature. Bulletin of the American Meteorological Society 74:1007-1023.
Kriticos, D.J., and R.P. Randall. 2001. A comparison of systems to analyze potential weed distributions. p. 61-79. In Groves, R.H., F.D. Panetta, and J. Virtue (eds.) Weed risk assessment. SCIRO Publishing, Melbourne, Australia.

Kurz, W.A., C.C. Dymond, G. Stinson, G.J. Rampley, E.T. Neilson, A.L. Carroll, et al. 2008. Mountain pine beetle and forest carbon feedback to climate change. Nature 452:987-990.

Liu, B.H., M. Xu, M. Henderson, Y. Qi, and Y.Q. Li. 2004. Taking China's temperature: daily range, warming trends, and regional variations, 1955-2000. Journal of Climate 17:4453-4462.

Neuvonen, S., P. Niemela, and T. Virtanen. 1999. Climatic change and insect outbreaks in boreal forests: the role of winter temperatures. Ecological Bulletin 47:63-67.

Parmesan, C., N. Ryrholm, C. Stefanescu, J.K. Hill, C.D. Thomas, H. Descimon, et al. 1999. Poleward shifts in geographical ranges of butterfly species associated with regional warming. Nature 399:579-583.

Peterson, A.T., R. Williams, and G.J. Chen. 2007. Modeled global invasive potential of Asian gypsy moths, Lymantria dispar. Entomologia Experimentalis et Applicata 125:39-44.

Porter, J.H., M.L. Parry, and T.R. Carter. 1991. The potential effects of climatic change on agricultural insect pests. Agricultural and Forest Meteorology 57:221-240.

Poutsma, J., A.J.M. Loomans, B. Aukema, and T. Heijerman. 2008. Predicting the potential geographical distribution of the harlequin ladybird, Harmonia axyridis, using the CLIMEX model. BioControl 53:103-125.

Roberts, E.A., F.W. Ravlin, and S.J. Fleischer. 1993. Spatial data representation for integrated pest management programs. American Entomologist 39:92-108.

Roy, D.B., and T.H. Sparks. 2000. Phenology of British butterflies and climate change. Global Change Biology 6:407-416.

Solomon, S., D. Qin, M. Manning, Z. Chen, M. Marquis, K.B. Averyt, et al. 2007. Contribution of working group I to the fourth assessment of the intergovernmental panel on climate change, 2007. Cambridge University Press, Cambridge, UK.

Stireman, J.O., L.A. Dyer, D.H. Janzen, M.S. Singer, J.T. Lill, R.J. Marquis, et al. 2005. Climatic unpredictability and parasitism of caterpillars: implications of global warming. Proceedings of the National Academy of Sciences of the United States of America 102:17384-17387.

Sutherst, R.W., G.F. Maywald, W. Bottomley, and A. Bourne. 2004. CLIMEX v.2, CD and user's guide. Hearne Scientific Software, Melbourne, Australia.

Tonnang, H.E.Z., R.Y.M. Kangalawe, and P.Z. Yanda. 2010. Predicting and mapping malaria under climate change scenarios: the potential redistribution of malaria vectors in Africa. Malaria Journal 9:111.

Tougou, D., D.L. Musolin, and K. Fujisaki. 2009. Some like it hot! Rapid climate change promotes changes in distribution ranges of Nezara viridula and $N$. antennata in Japan. Entomologia Experimentalis et Applicata 130:249-258

Tran, J.K., T. Ylioja, R.F. Billings, J. Régnière, and M.P. Ayres. 2007. Impact of minimum winter temperatures on the population dynamics of Dendroctonus frontalis. Ecological Applications 17:882-899.

Wen, L.Z., Y.J. Zhang, L. Zhu, S.L. Wang, Q. Xiao, and Z.X. Yang. 2011. Unbalanced cyclical fluctuation pattern of intermittent outbreaks of beet armyworm Spodoptera exigua Hübner in China. Acta Ecologica Sinica 31:2978-2989 (In Chinese with English abstract).

Zheng, X.L., W.J. Cheng, X.P. Wang, and C.L. Lei. 2011. Enhancement of supercooling capacity and survival by cold acclimation, rapid cold and heat hardening in Spodoptera exigua. Cryobiology 63:164-169.

Zheng, X.L., P. Wang, W.J. Cheng, X.P. Wang, and C.L. Lei. 2012. Projecting over-wintering regions of beet armyworm, Spodoptera exigua in China, using CLIMEX model. Journal of Insect Science 12:13. 